\title{
Effects of Angiotensin I Converting Enzyme Inhibitors on the Renal Excretory Function, Hemodynamics and Renin Release in Isolated Perfused Rat Kidney
}

\author{
Tohru Oginara, M.D., Mamoru Yoshizawa, M.D., \\ Toshiyuki Yasur, M.D., Haruyuki Nakane, M.D.,* \\ Yoko Nakane, M.D.,* and Takao Saruta, M.D.
}

\section{Summary}

Direct renal effects of angiotensin I converting enzyme inhibitors (CEIs), captopril, SA446 and MK421, were examined in isolated rat kidneys perfused with a renin-substrate-free medium. Among three CEIs, only captopril induced a significant natriuresis, whereas SA446 and MK421 did not. $U_{K} V$, renal vascular resistance and creatinine clearance were not affected by any of these CEIs. Renin release from perfused rat kidneys were not influenced by CEIs under the present experimental conditions.

Thesc results suggest that among three different types of CEIs, only captopril possesses natriuretic action in the isolated perfused rat kidney and that this action may be independent of its inhibitory action on angiotensin converting enzyme. It is also suggested that these three CEIs themselves do not have a direct effect on the renal vascular bed.

\section{Additional Indexing Words: Captopril SA446 MK421}

TN man and animals, it has been reported that CEIs induced natriuresis which seems disproportionate to the blood pressure level achieved by CEI administration. ${ }^{1-4)}$ The mechanism of CEI-induced natriuresis has been suggested to be related to the inhibition of angiotensin I converting enzyme (ACE).

Recently, we have reported that captopril induced natriuresis in isolated perfused rat kidney, in the absence of angiotensinogen, kininogen and aldosterone. ${ }^{5}$ This observation suggests that captopril-induced natriuresis in the isolated perfused rat kidney may be independent of its inhibitory action on

From the Department of Internal Medicine, School of Medicine, Keio University, Shinanomachi, Shinjuku-ku, Tokyo, and * the Department of Internal Medicine, Urawa City Hospital, Saitama.

Address for reprint: Takao Saruta, M.D., Department of Internal Medicine, School of Medicine, Keio University, 35, Shinanomachi, Shinjuku-ku, Tokyo 160, Japan.

Received for publication January 18, 1983. 


\section{Urine Volume (mean \pm S. E. M)}

Control

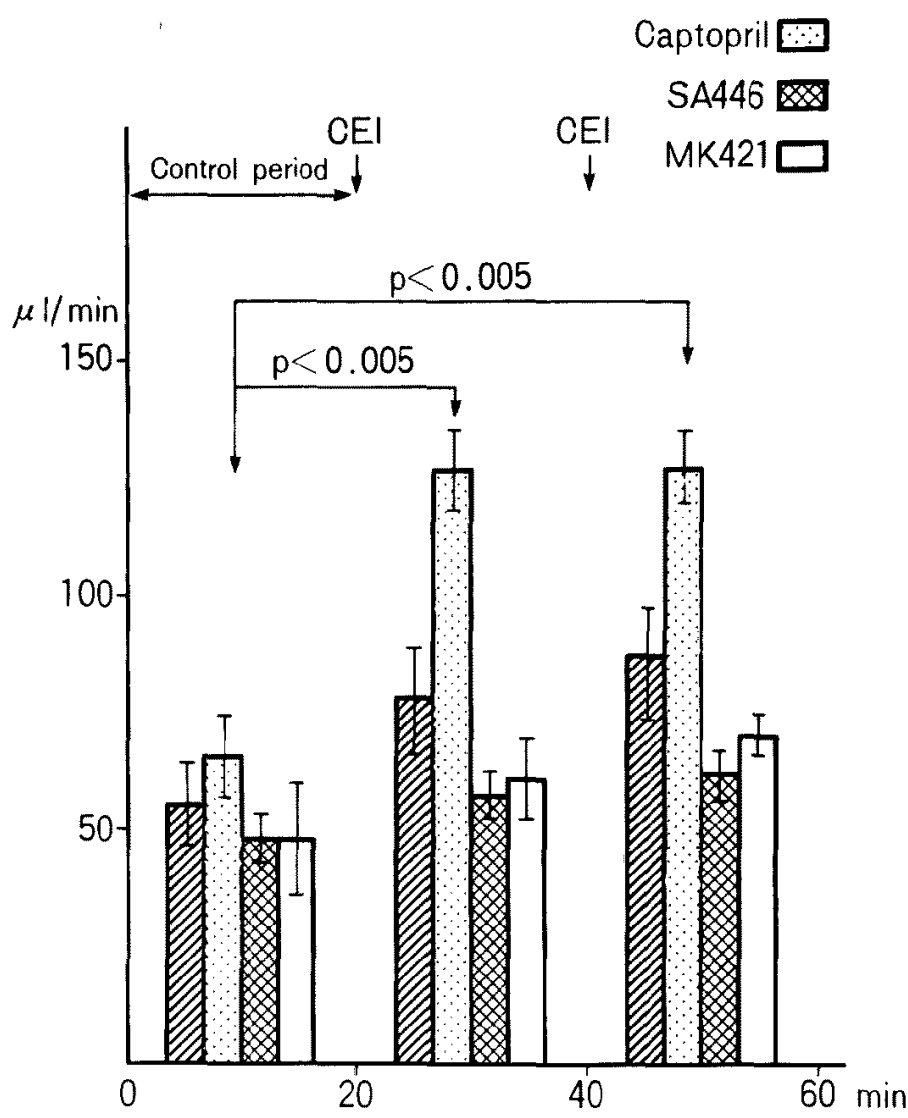

Fig. 1, Effects of captopril, SA446 and MK421 on urine volume in the isolated perfused rat kidney.

ACE or kininase II.

In order to further investigate the mode of direct renal action of CEIs, the effects of three different types of CEIs, captopril (Squibb Laboratories), SA446 (Santen Laboratories) and MK421 (Merck Sharp Laboratories), on renal hemodynamics and excretory function were examined in isolated perfused rat kidney. We also examined whether these effects are based on the blockade of local angiotensin II (AII) formation by studying renin release from the isolated kidneys.

\section{Materials and Methods}

Under pentobarbital anesthesia, following an injection of 100 units of 
$\mathrm{U}_{\mathrm{Na}} \mathrm{V}($ mean \pm S. E. M)

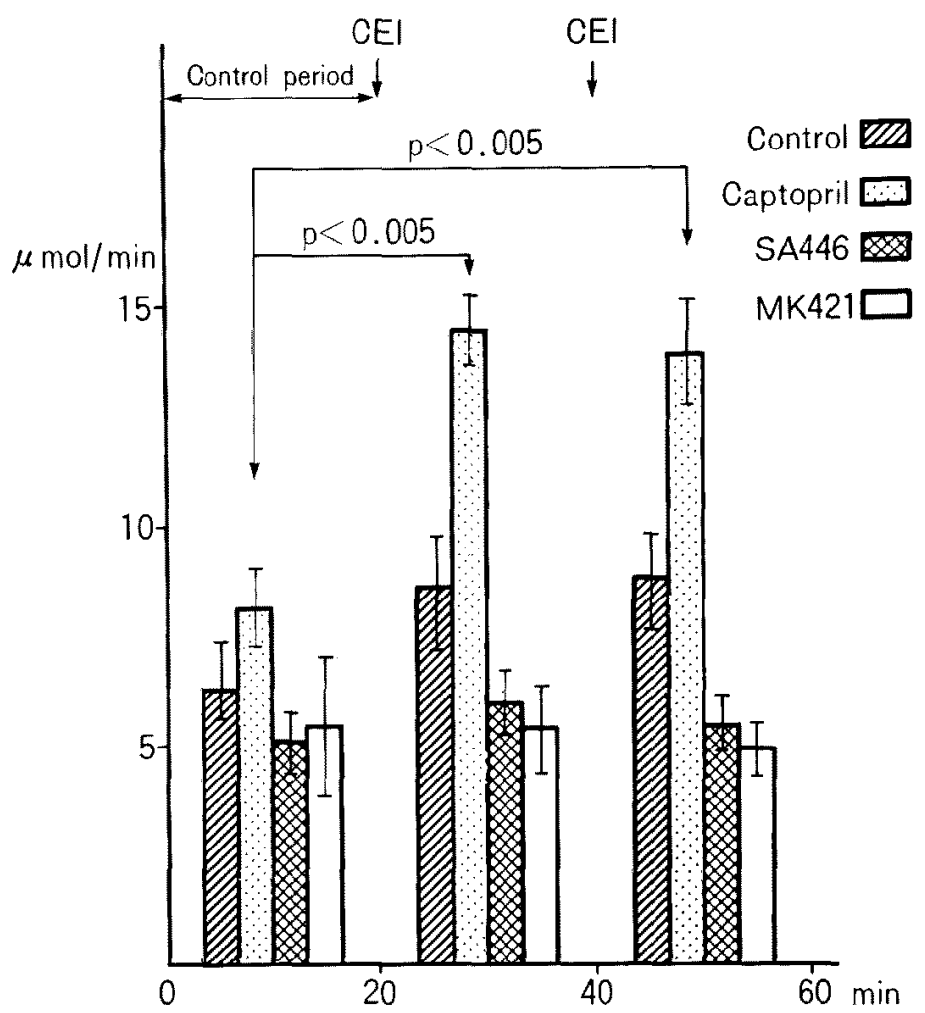

Fig. 2. Effects of captopril, S 4446 and MK421 on urinary sodium excretion $\left(\mathrm{U}_{\mathrm{N \Omega}} \mathrm{V}\right)$ in the isolated perfused rat kidney.

heparin into the jugular vein, the right kidney of male Wistar rats (weight, $300-450 \mathrm{Gm}$ ) was cannulated without interruption of blood flow, ${ }^{6)}$ isolated, and perfused in vitro at a stable perfusion pressure $(80 \mathrm{mmHg})$ with $75 \mathrm{ml}$ of recirculating Krebs-Ringer bicarbonate buffer containing $5 \%$ or fraction $\mathrm{V}$ bovine serum albumin, $5.5 \mathrm{mM}$ of glucose and $1 \mathrm{mg}$ of creatinine. ${ }^{7}$

Thirty-one rats were divided into 4 groups: control group $(\mathbf{n}=10)$, captopril-administered group $(n=6)$, SA446-administered group $(n=9)$, and MK421-administered group $(n=6)$. The observation period began after a 20 min-equilibration period. One $\mathrm{mg}$ of captopril, $2.0 \mathrm{mg}$ of SA446, or $2.2 \mathrm{mg}$ of MK421 was injected in the recirculating medium $\left(6.1 \times 10^{-5} \mathrm{M}\right.$, $6.0 \times 10^{-5} \mathrm{M}$, and $6.0 \times 10^{-5} \mathrm{M}$ in the perfusate, respectively) at 20 and $40 \mathrm{~min}$ of the observation period. The renal function and perfusate renin concentration were measured for 1 hour and compared with data from the control period (0-20 min). The glomerular filtration rate (GFR) was estimated by 


\section{$\mathrm{U}_{\mathrm{K}} \mathrm{V}(\operatorname{mean} \pm$ S. E. M $)$}

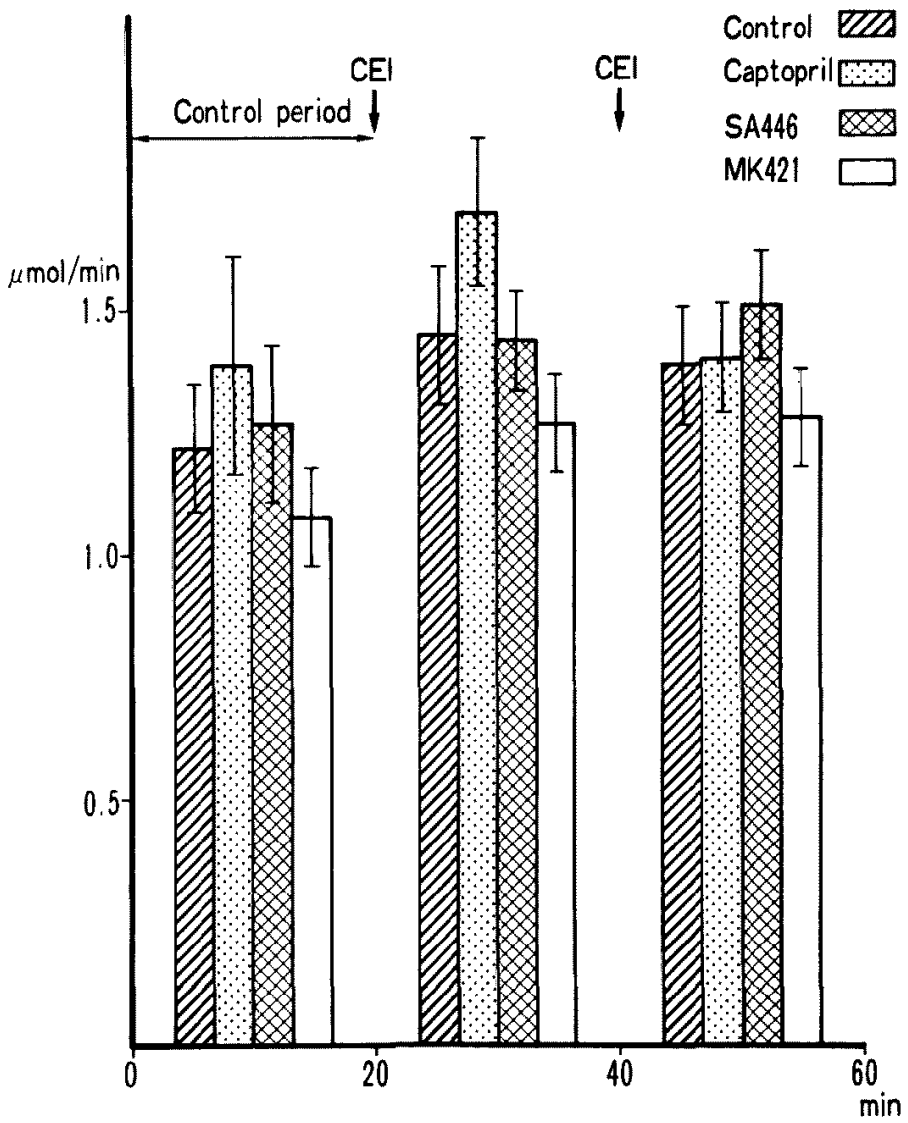

Fig. 3. Effects of captopril, SA446 and MK421 on urinary potassium excretion $\left(U_{K} V\right)$ in the isolated perfused rat kidney.

measuring creatinine clearance. The perfusate renin concentration was measured by a previously described method. ${ }^{8}$ ) Values are reported as means \pm SEM. A non-paired t-test was used to determine statistical significance.

\section{REsULTS}

As shown by Figs. 1-3, captopril induced significant increases in urine volume and $\mathrm{U}_{\mathrm{Na}} \mathrm{V}$, whereas slight changes in these variables induced by $\mathrm{SA} 446$ and MK421 were not statistically significant. $\mathrm{U}_{\mathrm{K}} \mathrm{V}$ was not affected by CEIs. Similarly, CEIs did not affect renal vascular resistance (Fig. 4). Although a gradual decrease in GFR was observed in all groups, there was no significant difference in GFR between the control group and CEI-administered 


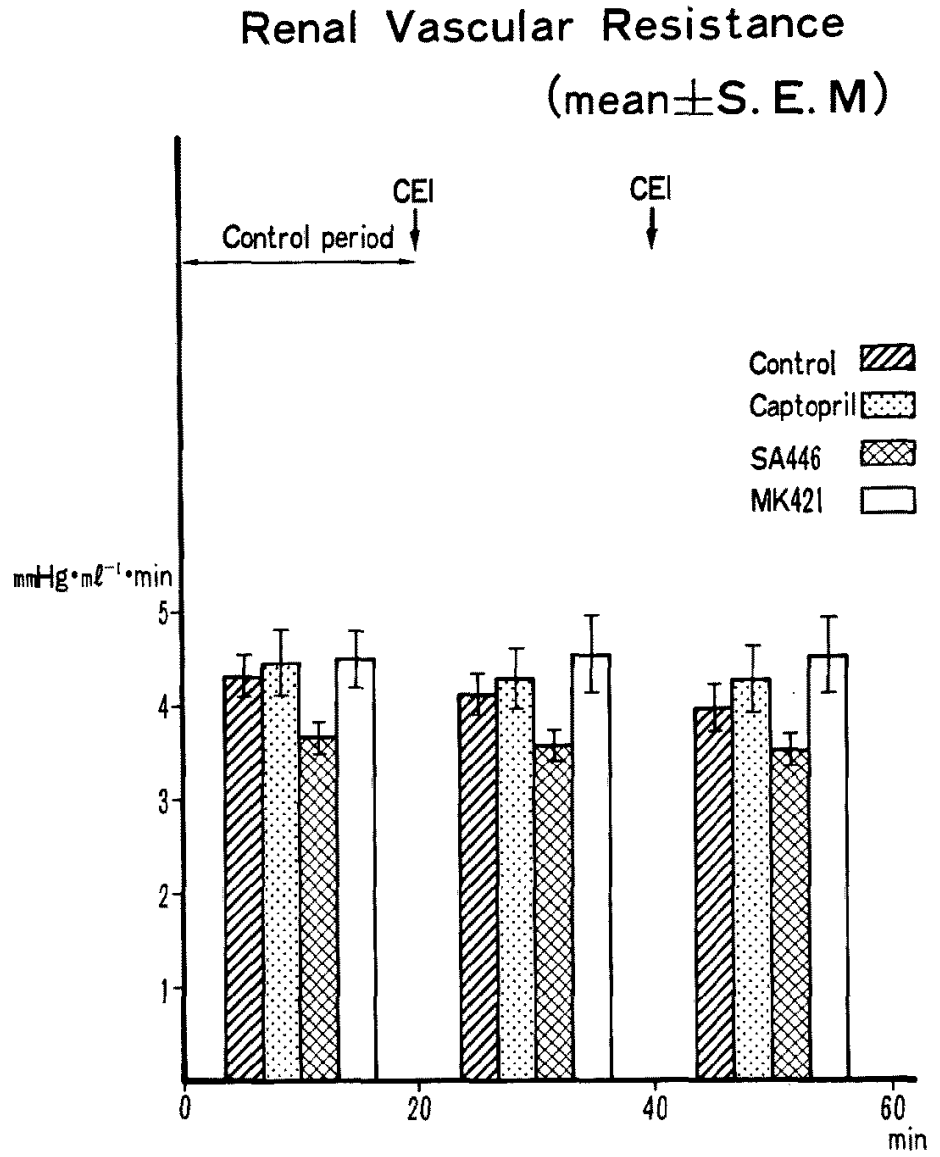

Fig. 4. Effects of captopril, SA446 and MK421 on renal vascular resistance in the isolated perfused rat kidney.

groups (Fig. 5). Fig. 6 shows the renin concentration in the recirculating medium of isolated perfused kidneys determined in control, captopril-administered and SA446-administered groups. In the CEI-administered groups tested, perfusate renin concentrations did not differ from the control group.

\section{Discussion}

In vivo studies in man and animals have reported that CEIs induce natriuresis and renal hemodynamic changes. ${ }^{1-4)}$ The possible mechanisms of CEI-induced natriuresis in vivo have been suggested as follows: (1) vasodilatory and tubular actions due to reduction of angiotensin II and/or accumulation of kinins, ${ }^{3), 91-16)}$ (2) vasodilatory and tubular actions due to stimulation of prostaglandin (PG) synthesis caused by an accumulation of kinins, ${ }^{17)-19}$ ) and (3) reduction of aldosterone. ${ }^{20), 21)}$ All these mechanisms are related to 


\section{Creatinine Clearance}

$($ mean \pm S. E. M)

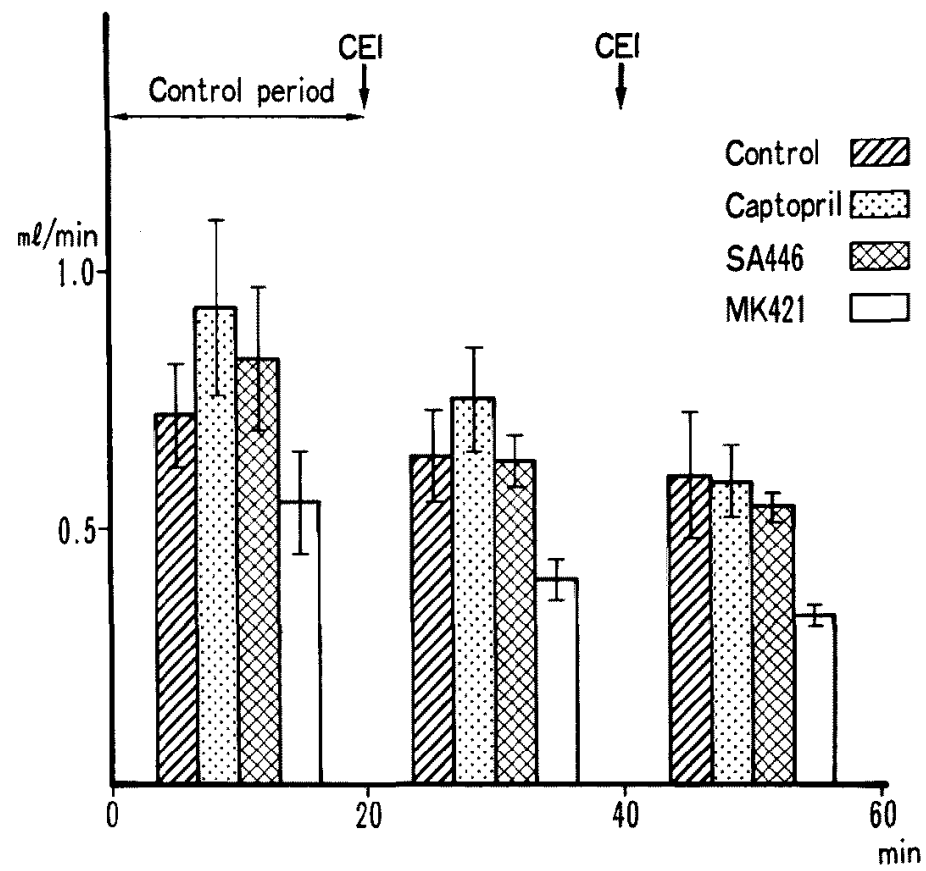

Fig. 5. Effects of captopril, SA446 and MK421 on crcatinine clcarance in the isolated perfused rat kidney.

the inhibition of ACE, and actions of CEIs other than ACE inhibition have been poorly documented.

In our previous study, we suggested that changes in circulating AII, kinins, PGs and aldosterone are not likely to be related to the captoprilinduced natriuresis in the isolated perfused rat kidney, since, in the isolated perfusion system, the perfusate lacks renin substrate, aldosterone and probably kininogen. ${ }^{5}$ However, it is possible that the formation of AII, kinins and PGs are still present within the isolated kidney and that the captopril-induced natriuresis may depend on its inhibitory action on intrarenal ACE. Among the three CEIs tested in the present study, only captopril induced a significant natriuresis, despite the fact that all three agents have similar ACE-inhibition properties. These three CEIs did not affect $\mathrm{U}_{\mathrm{K}} \mathrm{V}$, renal vascular resistance and creatinine clearance. This difference between captopril and SA446 and MK421 on renal action suggests that the natriuretic action of captopril may be independent of its inhibitory action on ACE in isolated perfused rat kidney. Moreover, the lack of significant stimulation of renin release in CEI-administered groups suggests that the effects of CEIs on intrarenal AII 


\section{Perfusate Renin Concentration (mean \pm S.E.M.)}

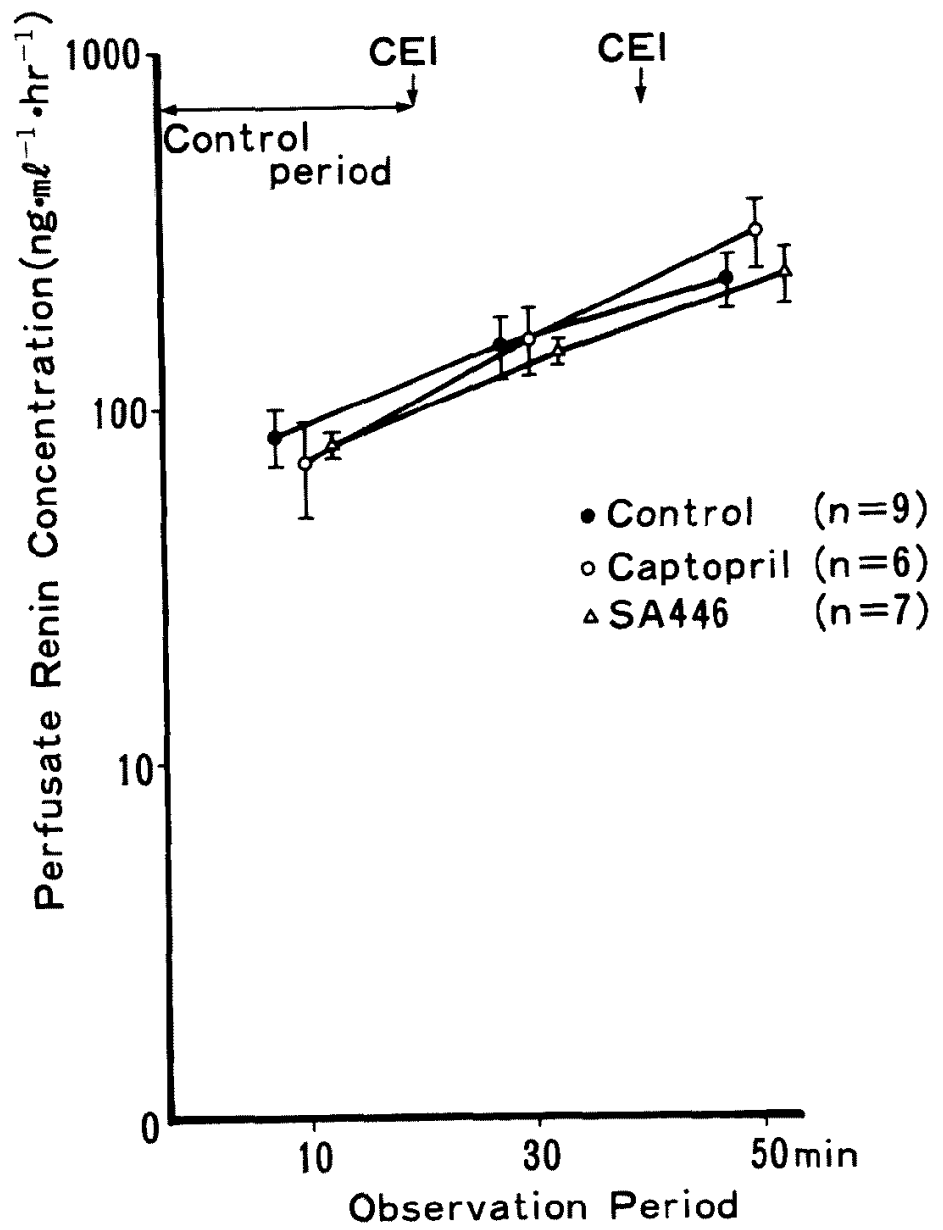

Fig. 6. Effects of captopril and SA446 on renin release in the isolated perfused rat kidney.

formation is negligible in this system for feedback contol of renin release by AII. Since renin release from the isolated kidney is not influenced by captopril and SA446 (compared with the control group), captopril-induced natriuresis in the isolated perfused rat kidney may be independent of its inhibitory action on local AII formation. 


\section{Acknowledgments}

We wish to thank Sankyo Co, Nippon Merck Co, and Santen Co for kind supply of captopril, MK421 and SA446, respectively.

\section{REFERENCES}

1. Nasjletti A, Colina-Chourio J, McGiff JC: Disappearance of bradykinin in the renal circulation of dogs: effects of kininase inhibition. Circulat Res 37: 59, 1975

2. Meggs LG, Hollenberg NK: Converting enzyme inhibition and the kidney. Hypertension 2: 551,1980

3. Bengis RG, Coleman TG, Young DB, McCaa RE: Long-term blockade of angiotensin formation in various normotensive and hypertensive rat models using converting enzyme inhibitor (SQ 14225). Circulat Res 43 (Suppl I): I-45, 1978

4. Mimran A, Casellas D, Dupont M: Indirect evidence against a role of the kinin system in the renal hemodynamic effect of captopril in the rat. Kidney Int 18: 746, 1980

5. Ogihara T, Yasui T, Nakane H, Nakane Y, Saruta T: Direct renal action of captopril (SQ 14225). Dissociation of natriuretic and vascular actions in isolated perfused rat kidney. Am J Cardiol 49: 1511, 1982

6. Nishiitsutsuji-Uwo JM, Ross BD, Krebs HA: Metabolic activities of the isolated perfused rat kidney. Biochem J 103: 852, 1967

7. Nakane H, Nakane Y, Reach G, Corvol P, Menard J: Aldosterone metabolism in isolated perfused rat kidney. Am J Physiol 234: E472, 1978

8. Menard J, Catt $\mathrm{KJ}$ : Measurement of renin activity, concentration and substrate in rat plasma by radioimmunoassay of angiotensin I. Endocrinology 90: 422, 1972

9. Harris PJ, Young JA: Dose-dependent stimulation and inhibition of proximal tubular sodium reabsorption by angiotensin II in the rat kidney. Pflügers Arch 367: 295, 1977

10. Harris PJ: The action of angiotensin III ([des-Asp $\left.{ }^{1}\right]$-angiotensin II) on proximal tubular sodium reabsorption in the rat kidney. in Hormonal Regulation of Sodium Excretion, ed by Lichardus B, Schrier RW, Ponec J, Elsevier/North-Holland Biomedical Press, Netherland, p 83, 1980

11. Navar LG, Huang W-C, Ploth DW: Influence of the renin-angiotensin system on sodium excretion in normal and Goldblatt hypertensive rats. in Hormonal Regulation of Sodium Excretion, ed by Lichardus B, Schrier RW, Ponec J, Elsevier/North-Holland Biomedical Press, Netherland, p 73, 1980

12. Barraclough MA, Jones NF, Marsden CD: Effect of angiotensin on renal function in the rat. Am J Physiol 212: 1153, 1967

13. Johnson MD, Malvin RL: Stimulation of renal sodium reabsorption by angiotensin II. Am J Physiol 232: F298, 1977

14. Hall JE, Guyton AC, Smith MJ, Coleman TG: Long-term regulation of arterial pressure, glomerular filtration and renal sodium reabsorption by angiotensin $I I$ in dogs. Clin Sci 59: $87 \mathrm{~s}, 1980$

15. Carretero OA, Scicli AG: Renal kallikrein: its localization and possible role in renal function. Federation Proc 35: 194, 1976

16. Carretero OA, Scicli AG: The renal kallikrein-kinin system. Am J Physiol 238: F247, 1980

17. Dunn MJ, Hood VL: Prostaglandins and the kidney. Am J Physiol 233: F169, 1977

18. Higashihara E, Stokes JB, Kokko JP, Campbell WB, DuBose TD: Cortical and papillary micropuncture examination of chloride transport in segments of the rat kidney during inhibition of prostaglandin production. Possible role for prostaglandins in the chloruresis of acute volume expansion. J Clin Invest 64: 1277, 1979

19. Stokes JB, Kokko JP: Inhibition of sodium transport by prostaglandin $\mathbf{E}_{2}$ across the isolated, 
perfused rabbit collecting tubule. J Clin Invest 59: 1099, 1977

20. Hollenberg NK, Meggs LG, Williams GH, Katz J, Gamic JD, Harrington DP: Sodium intake and renal responses to captopril in normal man and in essential hypertension. Kidney Int 2: 240, 1981

21. Brunner HR, Gavras H, Waeber B, Kershaw GR, Turini GA, Vukovich RA, McKinstry DN, Gavras I: Oral angiotensin-converting enzyme inhibitor in long-term treatment of hypertensive patients. Ann Int Med 90: 19, 1979 